\title{
Expression of Topoisomerase II- $\alpha$ protein in salivary gland tumors
}

\author{
ASAF SHVERO $^{1,2}$, OHAD HILLY ${ }^{2,3}$, GOLAN BUBIS $^{4}$, YANIV HAMZANY ${ }^{2,3}$, \\ RUMELIA KOREN $^{2,5}$ and LEA RATH-WOLFSON ${ }^{2,5}$
}

\author{
${ }^{1}$ Department of Urology, Sheba Medical Center, Tel Hashomer; ${ }^{2}$ Sackler School of Medicine \\ Tel Aviv University, Tel Aviv; ${ }^{3}$ Otolaryngology-Head and Neck Surgery, Rabin Medical Center, \\ Petah Tikva, Israel; ${ }^{4}$ St. George's University of London, University of Nicosia, Nicosia, Cyprus; \\ ${ }^{5}$ Department of Pathology, Hasharon Hospital, Rabin Medical Center, Petah Tikva, Israel
}

Received May 24, 2017; Accepted October 18, 2017

DOI: $10.3892 /$ mco.2017.1463

\begin{abstract}
Salivary glands give rise to approximately 30 histological distinct tumor types, which results in a diagnostic challenge for the pathologist. The present retrospective, immunohistochemical study aimed to evaluate the expression of Topoisomerase II- $\alpha$, a nuclear enzyme, as a diagnostic and prognostic marker in benign and malignant salivary gland tumors, including leomorphic adenoma, mucoepidermoid carcinoma, acinic cell carcinoma and carcinoma ex-pleomorphic adenoma. A total of 59 cases of benign and malignant salivary gland tumors were included in the present study. Representative paraffin-embedded sections were immunostained for Topoisomerase II- $\alpha$ (Topo II- $\alpha$ ). The expression level was semi-quantified for each case and then correlated with the histological diagnosis using hematoxylin and eosin-stained slides, grade of tumor and total survival. Significant differences were revealed between the expression level of Topo II- $\alpha$ in pleomorphic adenoma and mucoepidermoid carcinoma $(\mathrm{P}<0.001)$, carcinoma ex-pleomorphic adenoma $(\mathrm{P}<0.001)$, acinic cell carcinoma $(\mathrm{P}=0.005)$ and a group composed of all the malignant tumors $(\mathrm{P}<0.001)$. Cancer-specific survival rates were insignificantly increased in tumors expressing low levels of Topo II- $\alpha(\mathrm{P}=0.464)$. Thus, the present study demonstrated different expression levels of Topo II- $\alpha$ in benign and malignant salivary gland tumors. These differing expression levels may act as valuable biomarkers for the correct histological diagnosis. Further studies conducted on a larger scale may lead to even more conclusive results.
\end{abstract}

Correspondence to: Dr Golan Bubis, St. George's University of London, University of Nicosia, 93 Agiou Nicolau Street, Nicosia, Cyprus

E-mail: bubisgolan@gmail.com

Key words: Topoisomerase II- $\alpha$, salivary gland tumors

\section{Introduction}

Salivary glands give rise to no fewer than 30 histologically distinct tumor types. Over the years there has been some progress in clarifying specific causes of salivary gland cancer. The best known risk factor is that of radiation exposure as is evident in the increased risk of post-atomic bomb survivors and in patients who received therapeutic radiation (1). In the second half of the 20th century a considerable number of new entities of salivary gland tumor were added. These neoplasms are relatively uncommon, comprising $<2 \%$ of all tumors in humans. Approximately $65-80 \%$ arise within the parotid gland, $10 \%$ within the submandibular gland and the remainder in the minor salivary glands (2-5).

In the present study we investigated pleomorphic adenoma (benign tumor), mucoepidermoid carcinoma, acinic cell carcinoma, and carcinoma ex-pleomorphic adenoma. The histological diagnosis of salivary gland tumors was performed using hematoxylin and eosin (H\&E)-stained slides. The results showed different expression levels of Topo II- $\alpha$ in benign and malignant salivary gland tumors. These differing expression levels may act as valuable biomarkers for the correct histological diagnosis.

\section{Materials and methods}

Topoisomerase II- $\alpha$. Topoisomerase is a nuclear enzyme important for DNA replication, transcription, recombination, and mitosis. Topoisomerases introduce supercoils that release the strain caused by over winding. Type I Topoisomerases relax supercoiled structures while type II Topoisomerase (also known as DNA gyrase) can introduce negative supercoiling through coupling of ATP hydrolysis. Therefore, negative supercoiling is introduced by Topoisomerase II and relaxed by Topoisomerase I (6). Topoisomerase II has two isoenzymes, isoenzyme $\alpha$ exists only in proliferating cells and has been shown to be a marker for cell proliferation in normal and neoplastic cells (6-8). In addition, it is involved in different signaling pathways related to the cell cycle and apoptosis, such as extracellular signal-regulated kinase (ERK2) (9), NF- $\kappa \mathrm{B}$ (10), and others. Topoisomerase II- $\alpha$ 
(Topo II- $\alpha$ ) has been extensively researched for its role as a molecular target of chemotherapy agents. Several studies have suggested that Topo II- $\alpha$ expression is related to response to anthracycline treatment for breast cancer (11-13), renal medullary carcinoma (14), ovarian carcinoma (15), salivary gland tumors $(16,17)$, acute myeloid leukemia (18), Hodgkin's lymphoma (19), colorectal cancer (20), hepatocellular carcinoma (21), gallbladder carcinoma (22), prostate carcinoma (23), and other malignant tumors (24). Thus, these cancer types benefit from using Topo II- $\alpha$ as a prognostic marker, and also for individual tailored therapy.

Few articles available regarding the expression of Topo II- $\alpha$ in salivary gland tumors. The purpose of the current study was to determine whether the expression of Topo II- $\alpha$ can be used as a marker to differentiate between benign and malignant salivary gland tumors, and as a prognostic marker. To the best of our knowledge, our research is the most extensive one to examine the expression of Topo II- $\alpha$ in salivary gland tumors.

Patients. A total of 59 consecutive cases of salivary gland tumors, 34 women and 25 men (median age, 57 years), diagnosed at 'Rabin Medical Center' during the years 1991-2010, were examined. All the tumors were diagnosed following a superficial or radical parotidectomy, except one which was diagnosed after a base of tongue biopsy. Surgical specimens were obtained directly from the operation room, fixed in $4 \%$ buffered formaldehyde and embedded in paraffin for examination in conventional H\&E staining. The specimens were reviewed in order to confirm the diagnosis.

Immunohistochemistry. The representative paraffin embedded blocks were cut into $3-5 \mu \mathrm{m}$ sections. Immunostaining was carried out using an antibody commercial kit (cat. no. NCL-TOPOIIAp; Novocastra Laboratories Ltd., Newcastle upon Tyne, England), containing a mouse anti-rabbit polyclonal antibody against a recombinant protein corresponding to the C-terminal region of the Topo II- $\alpha$ molecule. The procedure was performed with an automated immunohistochemistry system (Ventana medical systems Inc., Tucson, AZ, USA) in accordance with the manufacturer's instructions. High-grade colon carcinoma specimens were used as control for stain adequacy. Sections of positive and negative control tissues and non-malignant tissue of the resected salivary gland specimen were also included.

Microscopy and staining evaluation. To assess the level of Topo II- $\alpha$ expression, five representative high power fields (x400) were examined. For each field, the percentage of positively stained nuclei was registered along with the intensity of the stain. The intensity was rated 0-3 (0, for no nuclear stain; 1 , for the weakest nuclear stain; and 3 , for the strongest nuclear stain) in comparison with the control stain. A score was calculated by multiplying the intensity of each field with the percentage of positively stained cells and then by a factor of 100 (i.e., if $20 \%$ of the nuclei in the slide was stained with an intensity of 2 the slide got a score of 40) (25). The mean score of five fields was named 'Topo II- $\alpha$ index' of the specimen. This was conducted by two independent observers (L.R.W and R.K.), and inter-observer concordance was $>95 \%$.
Statistical analysis. Our main aim was to assess Topo II- $\alpha$ expression as a diagnostic and prognostic marker. Sensitivity and specificity of the method in diagnosing malignant tumors were calculated, using the pathologic diagnosis as the 'gold standard'.

Survival curves were calculated for two groups divided by a cut-off Topo II- $\alpha$ index. One group comprised malignant tumors with an index above the cut-off index, while the second group comprised cases of malignant tumors with an index below the cut-off index. Survival curves were calculated using the Kaplan Meier method and the log rank test was used to test the difference between them to find the most significant cut-off index. Comparisons between the Topo II- $\alpha$ index of the two different groups (malignant vs. benign) were carried out using the Mann-Whitney U test. Multivariate logistic regression analysis was conducted to determine clinicopathological characteristics associated with a high expression of Topo II- $\alpha$. Data were arranged and analyzed using SPSS for Windows version 16 (SPSS, Inc., Chicago, IL, USA). The results are presented as a mean and standard deviation. The statistical significance level was set to 0.05 (two-tailed).

Ethics approval. The present study was approved by the local Ethics Committee in Rabin Medical Center, Petah Tikva, Israel (ministry of health approval no. 920100120). Procedures performed in studies involving human participants were in accordance with the ethical standards of the institutional and/or national research committee and with the 1964 Helsinki declaration and its later amendments or comparable ethical standards. For retrospective studies formal consent is not required.

\section{Results}

Patients. Clinicopathological data from 59 patients (34 men and 25 women) with salivary gland tumors were included in the present study, and the corresponding specimens were investigated for Topo II- $\alpha$ expression. The median age of the overall patient group was 57 years (interquartile range, 44-68 years) (Table I).

Histology. Of the total 59 tumors, 18 (30\%) were pleomorphic adenoma, 15 (24\%) were mucoepidermoid carcinoma, $13(22 \%)$ were acinic cell carcinoma, and $13(22 \%)$ were carcinoma ex-pleomorphic adenoma. All the tumors were stained for Topo II- $\alpha$. Nuclear stain was considered positive (Figs. 1 and 2).

Topo II- $\alpha$ expression. The mean expression levels of Topo II- $\alpha$, presented as the Topo II- $\alpha$ index, are provided in Table II. The highest expression of Topo II- $\alpha$ was in the carcinoma ex-pleomorphic adenoma tumors, with a range of 0.4-38.0. A significant difference $(\mathrm{P}<0.05)$ was found between the mean expression of Topo II- $\alpha$ in the normal salivary gland tissue and pleomorphic adenoma (Fig. 1) and mucoepidermoid carcinoma $(\mathrm{P}<0.001)$ (Fig. 2), acinic cell carcinoma $(\mathrm{P}<0.005)$, carcinoma ex-pleomorphic adenoma $(\mathrm{P}<0.001)$, and a group comprising all the malignant tumors $(\mathrm{P}<0.001)$. A Topo II- $\alpha$ index of 0.4 yielded a sensitivity of $76 \%$ and specificity of $94 \%$ in differentiating the pleomorphic 
Table I. Clinicopathological data of the study cohort.

\begin{tabular}{lccccc}
\hline Histological type & No. of cases & $\begin{array}{c}\text { Sex } \\
(\% \text { male })\end{array}$ & $\begin{array}{c}\text { Age, years } \\
(\text { median, IQR })\end{array}$ & $\begin{array}{c}\text { Tumor size, cm } \\
(\text { mean } \pm \text { SD) }\end{array}$ & $\begin{array}{c}\text { Positive surgical } \\
\text { margins }(\%)\end{array}$ \\
\hline Pleomorphic adenoma & 18 & 44 & $56,42-65.3$ & $2.8 \pm 1.2$ & 0 \\
Acinic cell carcinoma & 13 & 33 & $59,43.5-69$ & $3.1 \pm 0.7$ & 50 \\
Mucoepidermoid carcinoma & 15 & 23 & $52,33.5-61.5$ & $2.1 \pm 1.5$ & $3.0 \pm 1.0$ \\
Carcinoma ex-pleomorphic adenoma & 13 & 69 & $62,54-69$ & $2.8 \pm 1.2$ & 100 \\
Total & 59 & 42 & $57,44-68$ & & 25 \\
\hline
\end{tabular}

SD, standard deviation; IQR, intra-quartile range.

adenoma group from the group comprising all the malignant tumors.

Association between tumor grade and Topo II- $\alpha$ index. Table III shows the association between tumor grade and Topo II- $\alpha$ index. As the acinic cell carcinoma grading was not uniformly accepted, this tumor was excluded from this part of the analysis.

Survival. The mean follow-up for the entire cohort with malignant tumors was 9.1 years (range, 1.5-15). A total of 13 patients with malignant tumors died of their disease after an average of 4.5 years (range, 0.7-12.8). We searched for the most significant cut-off Topo II- $\alpha$ index to yield prognostic significance but we were limited by the relatively small study group and by other confounding clinic-pathological parameters known to have prognostic significance (like age and tumor size). Serial calculations were performed in order to find the most significant cut-off index thich was 2.0. Between the two groups (above and below the cut-off index) there was no significant difference in all tested clinicopathologic parameters (Table IV). The 5-year cancer-specific survival among the patients with an index $\geq 2.0$ was $68 \%$ ( 20 patients), compared with $85 \%$ for those with an index $<2.0$ (21 patients) (Fig. 3). This difference was not statistically significant (log rank test, $\mathrm{P}=0.464$ ).

\section{Discussion}

In this research, we set out to study the expression of Topo II- $\alpha$, in several salivary gland tumors. We found a statistically significant higher expression of Topo II- $\alpha$ in the malignant tumors group compared with the benign tumor pleomorphic adenoma, with an index of 0.4 having high sensitivity (76\%) and specificity (94\%) for malignancy. In a study by Maruya et al (17), a higher expression of the enzyme was demonstrated in malignant salivary gland tumors in comparison to common benign tumors, but the difference was not statistically significant due to a small study group (up to 7 cases of each malignant tumor).

Our results show that the enzyme is expressed at different levels in each type of malignant salivary gland tumor, the highest expression was observed in the carcinoma ex-pleomorphic adenoma group. This tumor is considered aggressive among salivary gland tumors, while the other two tumors we assessed are considered low grade tumors (2), and showed lower indices of the enzyme. Carcinoma ex-pleomorphic
Table II. Topo II- $\alpha$ index according to the histological type.

\begin{tabular}{lcc}
\hline Histological type & $\mathrm{n}$ & $\begin{array}{c}\text { Topo II- } \alpha \text { index } \\
(\text { mean } \pm \text { SD) }\end{array}$ \\
\hline Normal salivary gland & 16 & $0.50 \pm 0.30$ \\
Pleomorphic adenoma & 18 & $0.13 \pm 0.20$ \\
Acinic cell carcinoma & 13 & $1.81 \pm 2.58$ \\
Mucoepidermoid carcinoma & 15 & $6.41 \pm 10.91$ \\
$\begin{array}{l}\text { Carcinoma ex-pleomorphic } \\
\text { adenoma }\end{array}$ & 13 & $8.16 \pm 12.55$ \\
\hline
\end{tabular}

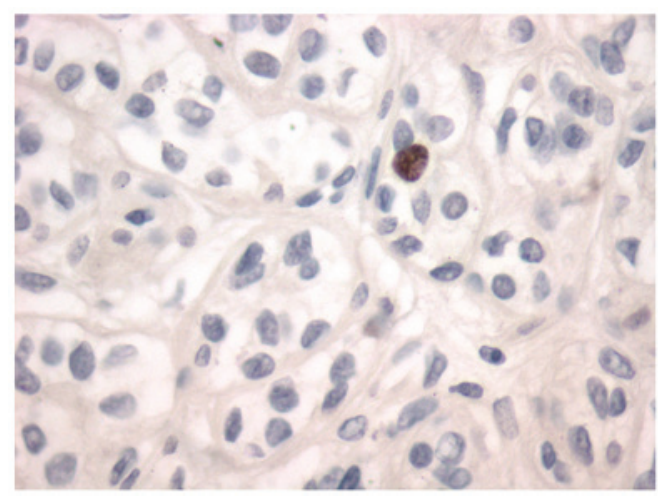

Figure 1. Topo II- $\alpha$ immunostained in pleomorphic adenoma. Note the nuclear stain in one cell. Magnification, x200.

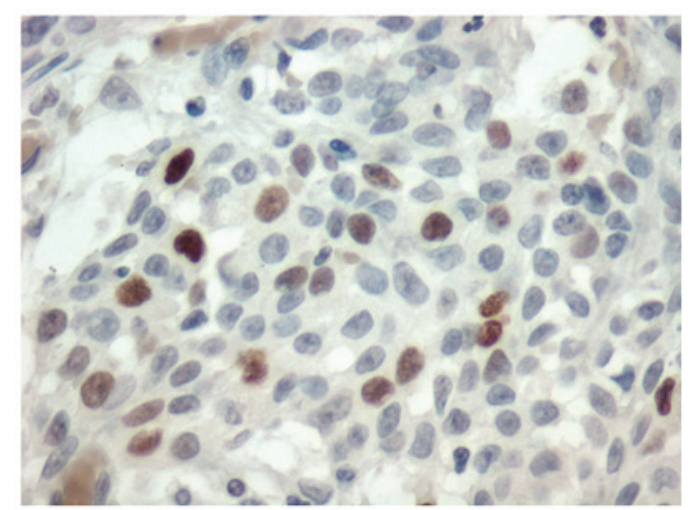

Figure 2. Topo II- $\alpha$ immunostained in Mucoepidermoid carcinoma. Note that there are several positive cells. Magnification, x200. 
Table III. Grade and Topo II- $\alpha$ index summation in mucoepidermoid carcinoma and carcinoma ex-pleomorphic adenoma.

\begin{tabular}{llcc}
\hline Histological type & Grade & $\begin{array}{c}\text { No. of } \\
\text { cases }\end{array}$ & $\begin{array}{c}\text { Mean topo } \\
\text { II- } \alpha \text { index }\end{array}$ \\
\hline $\begin{array}{llcc}\text { Mucoepidermoid } \\
\text { Carcinoma }\end{array}$ & $\begin{array}{l}\text { Low } \\
\text { Intermediate } \\
\text { and high }\end{array}$ & 6 & 2.13 \\
$\begin{array}{l}\text { Carcinoma } \\
\text { ex-pleomorphic } \\
\text { adenoma }\end{array}$ & Low & 2 & 8.91 \\
\hline
\end{tabular}

Table IV. Clinicopathological data of low and high Topo II- $\alpha$ index among malignant tumors.

\begin{tabular}{lccr}
\hline & \multicolumn{2}{c}{ Topo II- $\alpha$ index } & \\
\cline { 2 - 3 } & $<2.0$ & $\geq 2.0$ & P-value \\
\hline $\begin{array}{l}\text { Number of patients } \\
\text { Age (average in years) }\end{array}$ & 21 & 20 & \\
$\begin{array}{l}\text { Topo II- } \alpha \text { index } \\
\text { (average } \pm \text { SD) }\end{array}$ & $0.62 \pm 0.52$ & $10.6 \pm 12.3$ & $<0.001$ \\
$\begin{array}{l}\text { Tumor size } \\
\text { (average in cm } \pm \text { SD) }\end{array}$ & $2.5 \pm 0.94$ & $2.9 \pm 1.2$ & 0.241 \\
$\begin{array}{l}\text { Positive surgical margins } \\
\text { nonn }\end{array}$ & $61 \%$ & $61 \%$ & 0.981 \\
\hline
\end{tabular}

a5-year cancer-specific survival.

adenoma originates from the benign tumor Pleomorphic Adenoma, and can develop after decades in which the benign tumor was steady. And so, proper and efficient follow-up of patients suffering from pleomorphic adenoma, can lead to early diagnosis of the malignant transformation. Furthermore, in most cases, the malignant tumor presents with advanced disease stage III/IV, which gives us further motivation to early detection. These findings lead us to the conclusion that Topo II- $\alpha$ expression may be used as a clinical tool for early detection of malignant transformation, similar to previous researches conducted on p53 (26).

In addition, in the carcinoma ex-pleomorphic adenoma group (13 cases), we found 2 cases of low grade tumors, in which Topo II- $\alpha$ index was relatively low (1.1 in average) in comparison with the other 11 cases, which were of high grade, and showed much higher average index of 9.45. In the research of Maryua et al (17) their 3 cases of Carcinoma Ex-Pleomorphic Adenoma, had all very high Topo II- $\alpha$ expression. The expression of the enzyme in these tumors can imply on its biological behavior, and help us understand the nature of the tumor. In the future, it may lead to tailored treatment plans according to the tumor's immunohistochemical profile, and encourage research on targeted therapy, as is already carried out in other malignancies such as breast, colon, and lung cancer.

Mucoepidermoid carcinoma, being the most common malignant salivary gland tumor, is a subject of vast research.

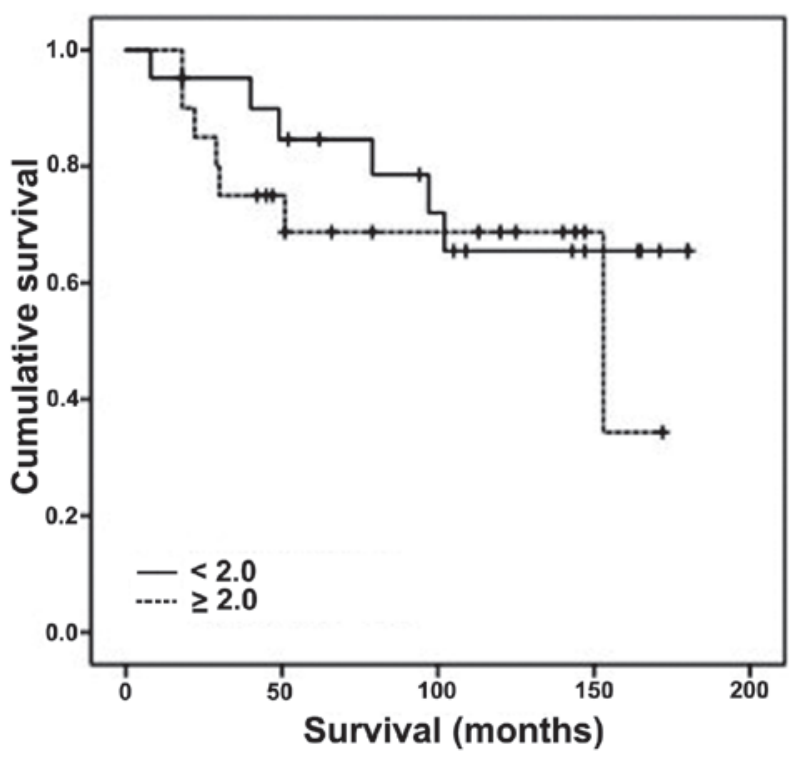

Figure 3. Cumulative total survival among patients with malignant tumors.

Many studies were conducted in order to clarify its genetic and morphologic heterogeneity and several immunohistochemical and genetic markers have been offered as prognostic and diagnostic markers $(27,28)$. Our results suggest Topo II- $\alpha$ as a differentiation marker between this tumor and pleomorphic adenoma. Furthermore, its expression may help us shed light on the biological behavior of the tumor. In addition, we found Topo II- $\alpha$ variable expressions in the different grades, similar to those results published by Maruya et al. In light of these results, it is possible that the role of Topo II- $\alpha$ in this type of tumor is complex.

The expression of Topo II- $\alpha$ in acinic cell carcinoma was the lowest among all malignant tumors we tested. In general, this tumor is considered to be of low grade, with slow and indolent course. Therefore, the relatively low level of Topo II- $\alpha$ expression matches the biological behavior of the tumor. Maruya et al (17) also found low levels of expression in this tumor type.

Survival rates were found to be higher in malignant tumors expressing low levels of Topo II- $\alpha$ (index less than 2.0), though not statistically significant. Higher cut-off values yielded significantly different survival rates, but also created groups with significant differences in other clinico-pathologic parameters known to affect prognosis (like age and tumor size). It is possible that with more homogeneous, larger studies, the level of Topo II- $\alpha$ expression may be proven to be of prognostic significance.

In the adjacent normal salivary gland, we found low levels of Topo II- $\alpha$ expression, with $93 \%$ of samples exhibiting some level of positive staining. These levels were higher than the ones measured in pleomorphic adenoma. We did not find other comparative studies regarding these data, and we cannot suggest any conclusions for this finding.

The present study is limited by its retrospective nature, its relatively small study group and by lack of homogeneity in the study group. 
To conclude, in salivary gland tumors, Topo II- $\alpha$ is expressed in different levels at different histological types. It may be used in the histological analysis of these tumors for differentiating benign from malignant tumors. A Topo II- $\alpha$ index $\geq 2.0$ is insignificantly associated with lower 5-year cancer specific survival rates. Salivary gland tumors with high Topo II- $\alpha$ index may warrant more aggressive modalities of therapy. Further studies need to be conducted for more conclusive results.

\section{References}

1. Zarbo RJ: Salivary gland neoplasia: A review for the practicing pathologist. Mod Pathol 15: 298-323, 2002.

2. Cheuk W and Chan JKC: Salivary Gland Tumors. In: Fletcher CDM. (eds). Diagnostic Histopathology of Tumors. 3rd edition. Philadelphia, Churchill Livingstone, pp239-326, 2007.

3. Lingen MW: Diseases of organ systems, salivary glands. In: Kumar V, Abbas AK, Fausto N. (eds). Pathologic Basis of Disease. 7th edition. Philadelphia, Elsevier Saunders, pp790-795, 2005

4. Rosai J: Major and Minor Salivary Glands. In: Rosai J. (eds). Surgical Pathology. 9th edition. Philadelphia, Elsevier Mosby, pp873-915, 2004.

5. Shvero A and Hadar T: Pathology of selected tumors of salivary gland. Med Connect 6: 29-34, 2011.

6. Berg JM, Tymoczko JL and Stryer L: DNA replication, recombination and repair. In: Berg JM, Tymoczko JL, Stryer L. (eds) Biochemistry. 5th edition. New York, W.H.Freeman \& Co, pp1119-1120, 2002.

7. Turley H, Comley M, Houlbrook S, Nozaki N, Kikuchi A, Hickson ID, Gatter K and Harris AL: The distribution and expression of the two isophorms of DNA topoisomerase II in normal and neoplastic human tissues. Br J Cancer 75: 1340-1346, 1997.

8. Hsiang YH, Wu HY and Liu LF: Proliferation-dependent regulation of DNA topoisomerase II in cultured human cells. Cancer Res 48: 3230-3235, 1988.

9. Shapiro PS, Whalen AM, Tolwinski NS, Wilsbacher J, Froelich-Ammon SJ, Garcia M, Osheroff N and Ahn NG: Extracellular signal-regulated kinase activates topoisomerase IIalpha through a mechanism independent of phosphorylation. Mol Cell Biol 19: 3551-3560, 1999.

10. Tabata M, Tabata R, Grabowski DR, Bukowski RM, Ganapathi MK and Ganapathi R: Roles of NF-kappaB and 26 $\mathrm{S}$ proteasome in apoptotic cell death induced by topoisomerase I and II Poisons in human non-small cell lung carcinoma. J Biol Chem 276: 8029-8036, 2001.

11. Nikolényi A, Uhercsák G, Csenki M, Hamar S, Csörgo E, Tánczos E, Thurzó L, Brodowicz T, Wagnerova M and Kahán Z: Tumor topoisomerase II alpha protein expression and outcome after adjuvant dose-dense anthracycline-based chemotherapy. Pathol Oncol Res 18: 61-68, 2012.

12. Gómez HL, Pinto JA, Olivera M, Vidaurre T, Doimi FD, Vigil CE, Velarde RG, Abugattas JE, Alarcón E and Vallejos CS: Topoisomerase II- $\alpha$ as a predictive factor of response to therapy with anthracyclines in locally advanced breast cancer. Breast 20 : 39-45, 2001.

13. Bartlett JM, Munro AF, Dunn JA, McConkey C, Jordan S, Twelves CJ, Cameron DA, Thomas J, Campbell FM Rea DW, et al: Predictive markers of anthracycline benefit: A prospectively planned analysis of the UK national epirubicin adjuvant trial (NEAT/BR9601). Lancet Oncol 11: 266-274, 2010.

14. Schaeffer EM, Guzzo TJ, Furge KA, Netto G, Westphal M, Dykema K, Yang X, Zhou M, Teh BT and Pavlovich CP: Renal medullary carcinoma: Molecular, pathological and clinical evidence for treatment with topoisomerase-inhibiting therapy. BJU Int 106: 62-65, 2010.
15. Ferrandina G, Petrillo M, Carbone A, Zannoni G, Martinelli E, Prisco M, Pignata S, Breda E, Savarese A and Scambia G: Prognostic role of topoisomerase-IIalpha in advanced ovarian cancer patients. Br J Cancer 98: 1910-1915, 2008.

16. Hirabayashi S: Immunohistochemical detection of DNA topoisomerase type II alpha and Ki-67 in adenoid cystic carcinoma and pleomorphic adenoma of the salivary gland. J Oral Pathol Med 28: 131-136, 1999.

17. Maruya S, Shirasaki T, Nagaki T, Kakehata S, Kurotaki H, Mizukami H and Shinkawa H: Differential expression of topoisomerase IIalpha protein in salivary gland carcinomas: Histogenetic and prognostic implications. BMC Cancer 9: 72, 2009.

18. Chen CC, Gau JP, You JY, Lee KD, Yu YB, Lu CH, Lin JT, Lan C, Lo WH, Liu JM and Yang CF: Prognostic significance of beta-catenin and topoisomerase IIalpha in de novo acute myeloid leukemia. Am J Hematol 84: 87-92, 2009.

19. Doussis-Anagnostopoulou IA, Vassilakopoulos TP, Thymara I, Korkolopoulou P, Angelopoulou MK, Siakantaris MP, Kokoris SI, Dimitriadou EM, Kalpadakis C, Matzouranis M, et al: Topoisomerase IIalpha expression as an independent prognostic factor in Hodgkin's lymphoma. Clin Cancer Res 14: 1759-1766, 2008.

20. Coss A, Tosetto M, Fox EJ, Sapetto-Rebow B, Gorman S, Kennedy BN, Lloyd AT, Hyland JM, O'Donoghue DP, Sheahan K, et al: Increased topoisomerase IIalpha expression in colorectal cancer is associated with advanced disease and chemotherapeutic resistance via inhibition of apoptosis. Cancer Lett 276: 228-238, 2009.

21. Wong N, Yeo W, Wong WL, Wong NL, Chan KY, Mo FK, Koh J, Chan SL, Chan AT, Lai PB, et al: TOP2A overexpression in hepatocellular carcinoma correlates with early age onset, shorter patients survival and chemoresistance. Int J Cancer 124: 644-652, 2009

22. Washiro M, Ohtsuka M, Kimura F, Shimizu H, Yoshidome H, Sugimoto T, Seki N and Miyazaki M: Upregulation of topoisomerase IIalpha expression in advanced gallbladder carcinoma: A potential chemotherapeutic target. J Cancer Res Clin Oncol 134: 793-801, 2008.

23. Hughes C, Murphy A, Martin C, Fox E, Ring M, Sheils O,Loftus B, and $\mathrm{O}^{\prime}$ Leary J: Topoisomerase II-alpha expression increases with increasing Gleason score and with hormone insensitivity in prostate carcinoma. J Clin Pathol 59: 721-724, 2006.

24. Dekel Y, Frede T, Kugel V, Neumann G, Rassweiler J and Koren R: Human DNA topoisomerase II-alpha expression in laparoscopically treated renal cell carcinoma. Oncol Rep 14: 271-274, 2005.

25. Rath-Wolfson L, Purim O, Ram E, Morgenstern S, Koren R and Brenner B: Expression of estrogen receptor $\beta 1$ in colorectal cancer: Correlation with clinicopathological variables. Oncol Rep 27: 2017-2022, 2012.

26. Ohtaké S, Cheng J, Ida H, Suzuki M, Ohshiro K, Zhang W and Saku T: Precancerous foci in pleomorphic adenoma of the salivary gland: Recognition of focal carcinoma and atypical tumor cells by P53 immunohistochemistry. J Oral Pathol Med 31: 590-597, 2002.

27. Nguyen LH, Black MJ, Hier M, Chauvin P and Rochon L: HER 2/neu and Ki-67 as prognostic indicators in mucoepidermoid carcinoma of salivary glands. J Otolaryngol 32: 328-331, 2003.

28. Shemirani N, Osipov V, Kolker A, Khampang $\mathrm{P}$ and Kerschner JE: Expression of mucin (MUC) genes in mucoepidermoid carcinoma. Laryngoscope 121: 167-170, 2011. 